\title{
Analysis of the Internal Environment of the Pharmaceutical Distributor Operation in Russia Using SWOT Analysis
}

\author{
O. V. Krylova*, T. M. Litvinova, L. I. Babaskina, D. V. Babaskin, O. V. Savinova \\ Department of Pharmacy, Sechenov First Moscow State Medical University, Moscow, Russia
}

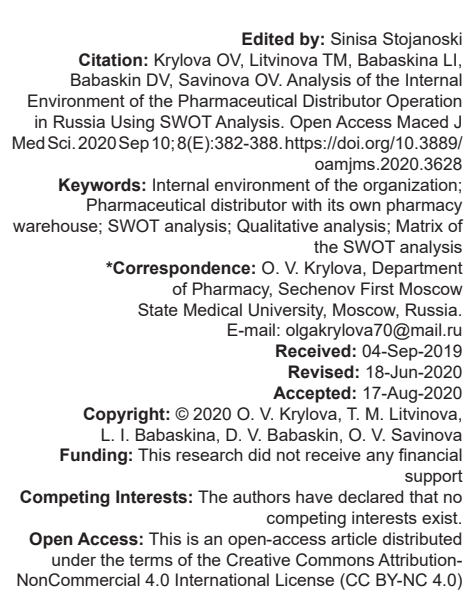

\section{Introduction}

The drug distribution market in Russia is undergoing major changes due to the creation of a single market within the EAEU, the introduction of the law on the mandatory labeling of drugs, and the import substitution policy under the "Pharma 2030" strategy [1]. Consequently, a marketing analysis is required of both the external market situation and internal resources for the implementation of strategic planning [2], [3], [4], [5], [6], [7], [8], [9], [10], [11]. Many authors [12], [13], [14], [15], [16], [17], [18], [19], [20], [21] use SWOT analysis as the main tool for managing the organization, since this method allows simultaneously analyzing the internal factors of the company (strengths and weaknesses) and external ones (threats and opportunities), and identifying the relationship between them, which will allow the organization to obtain a structured description of the current situation and determine appropriate development tactics [22], [23], [24], [25], [26], [27], [28].

A large sector in the pharmaceutical distributor market is occupied by pharmaceutical companies with their own pharmacy warehouse [29]. The internal structure of such organizations has certain specifics, which has its advantages and disadvantages. Therefore, it is necessary to highlight the universal parameters of the organization and the external environment that can be effectively applied in a SWOT analysis, which will allow any company of this type to assess whether its strengths are used as an advantage, whether its weaknesses are compensated, and also determine favorable circumstances for growth and primary threats.

Thus, the study is aimed at identification of strengths and weaknesses, opportunities and threats in the activities of a pharmaceutical distributor with its own pharmacy warehouse. 


\section{Materials and Methods}

To analyze the environment, the method of SWOT analysis was used during which a qualitative analysis of the internal factors characteristic of the pharmaceutical distributor with a pharmacy warehouse and their relationship with the external environment was carried out.

Strengths and weaknesses of the organization, opportunities and threats were identified by representatives of pharmacy warehouses. A wide range of factors was considered as an internal environment, including an analysis of personnel, facilities, equipment, and the organization's pricing policy. The external environment was studied from the perspective of developing and changing the structure of the pharmaceutical market, regulatory regulation, government support measures, and the socio-economic situation in the country.

Further, these parameters were compared by compiling a matrix. Its quadrants indicated the forces that allowed using the opportunities with the greatest benefit; forces that allowed effectively countering threats; weaknesses that limited the company's capabilities in the external environment; and weaknesses that carried high risks for the enterprise.

Based on the matrix obtained, recommendations were proposed for adjusting the weaknesses of the enterprise and countering the threats in the external market [22].

\section{Results and Discussion}

Let us consider the characteristic features of strengths and weaknesses of the operation of a pharmaceutical distributor with its own pharmacy warehouse. Strengths can be represented by the following indicators:

$\bullet$

S1. Company with a long record. A long record secures recognition and customer confidence.

- $\quad$ S2. Wide range in the price list and its constant expansion. Availability of a wide range of items in the price list allows attracting new customers and provides a wide selection for the existing customers

- $\quad$ S3. High wages. Higher wages in comparison with other organizations involved in pharmaceutical activities motivate employees of all levels to perform their duties better and eliminates the "staff turnover" typical of many Russian organizations.

- $\quad$ S4. Own premises of the pharmacy warehouse. It reduces the company's rental costs, which allows using the saved assets in other areas of development.

S5. Validation of warehouse processes. Warehouse thermal mapping. In practice, validation consists in testing the ability of certain engineering equipment in the warehouse (ventilation system, refrigeration units, etc.) to perform its functions in order to maintain storage conditions within acceptable limits. In turn, thermal mapping allows to determine such important factors as the location of the most critical areas of the space, subject to frequent temperature fluctuations due to the space structure and other factors, as well as to identify the most stable temperature zones of the warehouse, where it is recommended to store goods and place racks in accordance with the requirements for the products storage mode.

S6. Availability of the own pharmacy network. This indicator makes the company more stable and more competitive in the pharmaceutical market. Ten of the top ten distributors own one or more pharmacy chains. The development of own pharmacy chains provides an increase in sales channels and cost control; strengthening of regional presence and access to various price segments; and acquisition of partners in the retail market and capacity utilization [1].

S7. Availability of direct long-term contracts with domestic producers. It allows purchasing domestic drugs directly from producers, bypassing the extra links of the distribution chain. As a result, a competitive price can be offered in the market, and the maximum benefit from the sale can be obtained.

- $\quad$ S8. Flexible pricing. Non-linear pricing allows adapting to a wide variety of customers: Both large wholesalers and small retail customers.

- $\quad$ S9. Relatively low retail prices. In most cases, flexible pricing allows setting the price to include each group of customers in a competitive range (usually in the top five by price).

S10. Flexible system of arranging work with customers and suppliers. It allows optimizing the work process as much as possible, adapting to the partner and beginning cooperation immediately.

Let us analyze possible weaknesses of the organization engaged in pharmaceutical activities.

- W1. High costs of manual labor at the warehouse. Lack of the automatic assembly necessitates a large staff, and, as a result, additional units should be formed to control the ever-increasing number of employees.

W2. Lack of specialists in the pharmaceutical warehouse validation. Without observing the drugs storage and transportation conditions, 
there can be no confidence in the quality, safety, and effectiveness of drugs.

- W3. Significant load on a manager. The need to perform work beyond one's competence leads to a deterioration in the quality of immediate duties.

- W4. Lack of foreign economic activities. A sufficiently large number of domestic products are exported to the CIS countries and other developing countries that do not have their own high-quality pharmaceutical production. The lack of the foreign economic activities means the loss of customers settling in a stable international currency, as well as the loss of customers - major players in the domestic market of the importing country.

W5. No branches in other cities. There are also big losses of customers: Pharmacy chains, small- and medium-sized wholesalers located in other regions of the country, which cannot afford additional cost of transportation from the central region of the country to the local market.

- $\quad$ W6. Too many top managers. Due to the growing administrative dimension of the company, there can be one subordinate per manager.

W7. Lack of analytical and marketing departments. The procurement department takes over the function of marketing and market analysis in many pharmaceutical organizations. As a result, as the range of positions grows, managers perform triple work and do not always cope with it because of the increased duties and responsibilities.

W8. Lack of career growth. A situation when fairly strict work requirements are presented to a new employee has arisen in many companies. If the employee is doing well, the company appreciates their work and initiatives, but further career growth stops, as the employee is no longer considered for another, higher position. The employee is doing his job very well, but his promotion is a risk: Whether he will cope with new responsibilities, and whether a competent employee will replace him. Due to the unstable situation in the country's economy, many customers fail and declare themselves bankrupt, or continue operating but do not cope with the accumulated debts. W10. Lack of direct contracts with well-known foreign drug producers. No direct contracts with producers force the company to purchase their drugs from third parties, sometimes through many intermediaries, which increases the price while reducing competitiveness and the company's profit.

W11. Underdeveloped marketing information system. This problem is common to the entire pharmaceutical market. If large distributors cope with this problem, all their positive results are leveled with the inability to resolve this problem with their partners for various reasons. Moreover, due to high competition, companies are not always eager to share information with their partners. As such, the burden of the obligation to provide marketing information often rests with the very first links in the trade chain - producers.

Let us consider the opportunities of the pharmaceutical distributor with its own pharmacy warehouse.

- $\quad$ O1. Increasing number of domestic drugs. The development of the domestic pharmaceutical industry has been a priority socioeconomic task of the state since the introduction of import substitution [3].

- $\quad$ O2. High growth of the pharmaceutical market. The pharmaceutical market is a dynamically developing sector of the global economy. According to the data of the Monthly Retail Audit of the Russian Pharmaceutical Market conducted by DSM Group marketing agency, 5.3 bln packages of drugs worth about 991.9 bln rubles (in retail prices) were sold through pharmacies in 2018. The drug sales grew by $4.6 \%$ in value and $4.9 \%$ in kind compared to 2017 [4].

- O3. Organization of auctions for procurement of drugs funded from the budget. The state is the largest and most stable player in the pharmaceutical market - therefore, cooperation with state agencies is a $100 \%$ guarantee of the return on procurement funds.

04. Growing number of pharmacies, drugstores, and kiosks. Increasing number of potential customers. According to experts, the number of drugstores in Russia has grown by $175 \%$ over the past 3 years. In particular, according to statistical indicators, there is one pharmacy per 1800 inhabitants [30]. This indicator influences the number of potential customers for the operation of the pharmaceutical distributor under study.

O5. Decrease in the number of competitors due to the unstable economic situation. As mentioned above, not all companies are able to withstand competition in the current economic situation. The decreasing number of competitors provides an opportunity to occupy their niche in the market or to allow own customers to occupy it, thereby indirectly boosting the company's profit.

O6. Poor policy of competitors. Like withdrawal from the market, the poor policy of competitors enables the company to occupy new niches and attract new customers, thereby increasing 
its market share. It is important that the wrong behavior is much more common than a decrease in the number of competitors, but at the same time, the share of the increase in its influence is less.

- $\quad$ 07. Including new types of products and expanding the range. With a constantly evolving market and the appearance of new types of products, it is important to respond in time, correctly evaluate, and possibly introduce new products to the market, if they are cost-effective.

- $\quad$ 08. Minimizing stock by pharmacies. It is a very important factor: Due to constant price fluctuations, retail, and wholesale customers try minimizing the product balance, thus increasing the frequency of purchases, which, with the right pricing policy, and brings regular loyal customers.

- $\quad$ 09. Development of information technology. The company is able to achieve significant saving having correctly and timely introduced information technology into its operations. Unfortunately, it is often necessary to instantly invest a tangible amount of money to implement a new technology, and it is important to estimate the benefits for the company from this investment in the future.

- 010. Development and improvement of automated accounting systems. The growth of the company, opening of new pharmacies and new departments, as well as increases in stock and sales all contribute to the increase in the array of information that needs to be constantly processed. The introduction of an automated accounting system and, just as importantly, its correct setup and proper use can save a company a considerable amount of money.

The next stage of our study is the identification of threats to the operation of the pharmaceutical distributor with its own pharmacy warehouse.

$\bullet$

T1. Instability of the national currency. The company may go bankrupt if it fails to predict the changes in the national currency rate in time and take appropriate measures (producers usually import substances and therefore settle in foreign currency).

- $\quad$ T2. Inflation development. A high inflation rate (in 2019, inflation [3\%] took second place in the entire history of observations, it was lower only in $2017-2.5 \%$; in 2018 , inflation was $4.3 \%$ [31]) primarily impacts the bank rate its appreciation means an increase in the loan interest rate, and, consequently, an increase in the cost of products for the customer in the long term. Most large customers "force" suppliers to provide them with a deferment (according to the Pareto rule, such customers are the most profitable), and sales volume decreases due to price increases - as a result, the company's profit falls.

T3. Acute competition. The pharmaceutical market has always existed in the conditions of fierce competition of its players. However, competition for the vacated space only intensifies after the withdrawal of players from the market, which are often very large. According to the DSM Group marketing agency, in 2018, the number of pharmaceutical distributors in the Russian market was more than 400 , with the exception for microenterprises [1].

T4. Delays in financing budget organizations. This unpleasant situation can turn out very painful for the company due to the delay in financing state-owned enterprises during the crisis. As a result, payment for supplies to a state-owned institution will be refunded, but due to delays in financing and the abovementioned fluctuations in the national currency and inflation, the company will lose in value while receiving full payment in quantitative terms.

- T5. Insolvency of some retail customers. This problem for the company originates not from the beginning of the trade link but from its end. Commercial retail organizations are the second last link of the entire trade chain, and this is the majority of consumers in the country. Their insolvency will eventually affect the distributor.

- T6. Unemployment growth. In September 2018, unemployment rate amounted to $4.5 \%$. As a result of Federal State Statistics Service [31], welfare per capita falls, and the purchasing power of the population declines. T7. Change in prices. This criterion is closely related to the stability of the national currency. A sharp fall in prices for products will lead to stagnation of products in the warehouse until the previous cheap consignments of products and their analogues are "washed out" from the market, which increases the cost of their logistics and storage.

Let us build a matrix of the qualitative SWOT analysis following the identification of strengths and weaknesses, opportunities and threats to the operation of the pharmaceutical distributor with its own pharmacy warehouse (Table 1).

\section{Discussion}

An analysis of the internal potential of a pharmaceutical company makes it possible to determine its strengths and weaknesses in business, to assess their relationship with external factors. 
Table 1: Matrix of the qualitative SWOT analysis

\begin{tabular}{lll}
\hline Opportunities & Threats \\
\hline Strengths & S1-O3; S1-O4; S1-O5; S1- O6; & S1-T3; \\
S2-O7; & S2-T2; S2-T5; S2-T7; \\
S3-O5; & S3-T6; \\
S4-O3; & S4-T1; S4-T2; \\
S5-O3; S5-O7; S5-O8; & S5-T1; S5-T2; \\
S6-O1; S6-O7; S6-O8; & S6-T3; S6-T5; \\
S7-O1; S7-O2; S7-O3; S7-O9; & S7-T3; \\
S8-O2; S8-O3; S8-O4; S8-O9; & S8-T3; \\
S9-O1; S9-O2; S9-O3; S9-O4; & S9-T1; S9-T2; S9-T3; S9-T4; \\
S9-O6; S9-O7; & S10-T1; S10-T2; S10-T3; S10-T4; \\
S10-O9; S10-O10 & S10-T7 \\
W1-O9; W1-O10; & W1-T3 W2-T3 W3-T3 W4-T1 W4-T2 \\
W2-O8; & W5-T1 W5-T2 W6-T1 W6-T2 W7-T3 \\
W3-O9; W3-O10; & W8-T3 W8-T6 W9-T4 W9-T5 W9-T7 \\
W4-O5; W4-O6; W5-O5; W5-O6; & W10-T3 W10-T7 W11-T3 \\
W6-O1; W6-O2; W6-O4; W6-O7; & \\
W7-O5; W7-O6; W7-O9; W7-O10; & \\
W8-O2; & \\
W9-O2; & \\
W10-O3; W10-O9; W10-O10; & \\
W11-O9; W11-O10 & \\
\hline
\end{tabular}

The strengths of the organization engaged in pharmaceutical activities are the advantages and benefits that distinguish the company from its competitors. Weaknesses are the enterprise's shortcomings that need to be fixed so that competitors cannot use them as their advantages.

The main task of the external analysis is to identify and understand the opportunities and threats that may occur for the considered organization in the present or arise in the future. Opportunities of the organization are positive factors (trends and phenomena) of the external environment, which can lead to an increase in sales and profits. Threats are negative factors (trends and phenomena) of the external environment, which can lead to a significant decrease in sales and profits in the absence of an appropriate reaction of the organization.

The ultimate goal of external analysis is the formation of alternative strategic decisions, their assessment and the final choice of strategy [30], [31], [32], [33], [34], [35], [36], [37], [38]. These decisions should be focused on the use of opportunities and protection against threats associated with changes in the external environment.

The decision matrix is the result of SWOT analysis that allows developing and taking decisions that can help using the identified opportunities and neutralize threats [12],[13], [14], [15], [16], [17], [18], [19], [20], [21].

The "Strengths - Opportunities" field reflects the use of the company's strengths to get a return on opportunities. This field presents options of company development strategies.

The "Strengths - Threats" field shows which strengths of the company can be used to eliminate identified threats.

The "Weaknesses - Opportunities" field allows identifying ways to overcome the company's weaknesses by implementing external opportunities.

The "Weaknesses - Threats" field reflects strategic initiatives, namely, the need to minimize the company's weaknesses to avoid threats from the external environment.

Based on the results of the analysis, strengths and weaknesses, as well as opportunities and threats to the pharmaceutical distributor can be compiled. Thus, a complete picture of the SWOT analysis is provided.

Let us analyze the relationship of the aboveindicated factors with the external environment. First, we consider the possible strengths of the company and determine the tactics of their use in the pharmaceutical market.

One of the significant advantages of the company is its long history as this determines company vision and inspires confidence in it. In connection with the current policy of import substitution, the growth of the retail sector of the pharmaceutical industry, this fact allows easier and faster establishing partnerships with the other market players. This will reduce the threat of competition, especially against the backdrop of the current economic situation, as weak wholesale organizations depart from the industry due to their incorrect policies.

One of the tactics of market development is to expand the assortment of the company. However, when implementing such a strategy, it is necessary to conduct full risk-benefit assessment since this implies serious economic threats due to the observed inflation, insolvency of retail customers, change in the price level of the manufacturer caused by the import of most of the substances.

High wages will be an indisputable advantage of the organization in the labor market; however, due to an unstable economy, an analysis of the feasibility and ability of the company to maintain it at a sufficiently high level is necessary.

The advantage will be the ownership of a pharmacy warehouse that complies with all GDP standards, i.e., it has been validated and thermomapped, as this provides advantages both in organizing tenders at the expense of budget funds and in issuing state benefits and subsidies.

Own pharmacy network is available only to large market players due to high economic costs but this gives them advantages in marketing products, the ability to minimize their own inventories.

A fundamental fact will be the long-term contracts with suppliers of goods. This guarantees to company continuous supply and helps to survive in a competitive environment.

A similar approach should be developed for customers; the main methods for achieving this goal will be flexible pricing policy and relatively low selling prices.

The above factors will be achievable with the flexible system for setting up work with customers and suppliers. The current level of information technology 
development, design, and improvement of automated accounting systems allows effectively implementing this.

Thus, if the company is characterized by most of the above factors, such threats as competition in the pharmaceutical market, instability of the national currency, retail insolvency, price increases, and high unemployment rates can be reduced.

Let us analyze significant shortcomings of the organization, the risks associated with them, and the possibilities for eliminating them.

A significant problem for the company is personnel problems such as lack of validation specialists, high manual labor costs at the warehouse, and significant burden on one manager. This carries threats associated with increased competition. However, the lack of qualified personnel can be reduced by introducing automated accounting systems and other information technologies.

Organizations should also pay attention to expanding the geography of their activities since lack of foreign economic activity and branches in other cities reduce the company's opportunities. In an unstable economy, with the observed decrease in the number of competitors, company possessing necessary resources should react quickly.

In the conditions of a dynamically changing market, it is necessary to constantly evaluate the organization's personnel policy with a view to optimizing it, identifying personnel reserve and rotating staff. Often there is an excess of managerial staff and the absence of marketing and analytic departments, which entails lack of strategic planning and insufficient development of the marketing information system. The latter affects the presence of contacts with well-known foreign manufacturers of drugs; therefore, the company loses profit.

Due to rising prices from suppliers, delays in financing of budgetary organizations and insolvency of the retail chain, a company may have serious problems with high and constantly growing level of receivables.

Thus, the above-indicated internal factors reduce the opportunities for company development and expose it to threats from competitors, inflation, and constant increase in the level of prices for drugs. However, there are opportunities to reduce them, such as the dynamic growth of the national pharmaceutical market, government policies to reduce the import of drugs, and the development of information technology and automation capabilities.

\section{Conclusion}

The main goal of this study was to identify the strengths and weaknesses, opportunities, and threats in the operation of a pharmaceutical distributor with its own pharmacy warehouse for drugs and pharmacysold products. The possible weaknesses and strengths of the pharmaceutical organization have been identified using the SWOT analysis, with a particular attention paid to the analysis of the weaknesses that can be turned into strategies to increase the company's advantages in the market. The opportunities and threats that the pharmaceutical business may face were described next.

As such, the analysis of the obtained information and the quality of the decision made directly depend on the completeness and reliability of the collected information and the correct use of the methods and techniques for analyzing this information. Identification of weaknesses and threats, as well as their compensation with strengths and opportunities will lead to an increase in the profitability of a pharmaceutical distributor if it seeks to develop its activities, expand its markets, increase its product range, improve technologies, and thus increase sales and profits.

\section{References}

1. Distribution of Drugs in Russia. Available from: https://www. ey.com/Publication/vwLUAssets/ey-blitz-survey-distribution-ofpharmaceuticals-in-russia/\$FILE/ey-blitz-survey-distribution-ofpharmaceuticals-in-russia.pdf. [Last accessed on 2020 Aug 20].

2. Vesnin VR. Management. Moscow: Prospect; 2009.

3. Chevallier J, lelpo F. The Economics of Commodity Markets. Chichester, West Sussex: John Wiley \& Sons; 2013.

4. Clow KE, James KE. Essentials of Marketing Research: Putting Research into Practice. Thousand Oaks, Calif: SAGE Publications, Inc.; 2013.

5. Norm J. Adaptive Marketing: Leveraging Real-time Data to Become a More Competitive and Successful Company. New York: Palgrave Macmillan; 2015. https://doi. org/10.1057/9781137462930

6. Kerin R, Hartley S, Rudelius W. Marketing. $12^{\text {th }}$ ed. New York: McGraw-Hill Education; 2014.

7. Pride WM, Ferrell OC. Marketing 2016. $18^{\text {th }}$ ed. United States: Cengage Learning; 2016.

8. DSM Group. Itogi 2018 Goda. Results of 2018. Retail Segment of the Russian pharmaceutical market; 2019. Available from: https://www.dsm.ru/news/566. [Last accessed on 2020 Aug 20].

9. Demidova A. Pharmacy Chains Want to Limit Their Market. Vedomosti; 2016. Available from: https://www.vedomosti.ru/ business/articles/2016/07/21/649998-aptechnie-seti-ogranichit.

10. Sergeyeva NM, Reprintseva YV. Marketing strategies of a pharmaceutical organization. Pharm Pharmacol. 2015;5(12):60-3.

11. Development Strategy of the Pharmaceutical Industry of the Russian Federation for the Period Through to 2020. Available from: http://www.pharma2020.ru. [Last accessed on 2020 Aug 20].

12. Dolgova IG, Shchepin VO, Proklova TN. Features of the application of SWOT analysis technology to assess the state of the regional system of organization of ophthalmological care for the population of the Tyumen region. Probl Soc Hyg Health Care 
His Med. 2016;24(6):330-4.

13. Marketing Concepts. Available from: http://www.ime-link.ru/ concept. [Last accessed on 2020 Aug 20].

14. Kosyakova NV. Pharmaceutical support for patients with orphan diseases in the subjects of the Southern Federal district: Strengths and weaknesses. Pharmacy. 2018;67(1):36-40.

15. Patrakhina TN. SWOT-analysis as a tool for planning the strategy of an educational organization. Intern J Sci Sci. 2015;7(2). https://doi.org/10.15862/08pvn215

16. Ahmadi M, Dileepan $P$, Wheatley KK. A SWOT analysis of big data. J Educ Bus. 2016;91(5):289-94. https://doi.org/10.1080/0 8832323.2016.1181045

17. Hollensen S. Global Marketing. $6^{\text {th }}$ ed. United Kingdom: Pearson Education Limited; 2013.

18. Kerin RA, Hartley SW. Marketing: The Core. $6^{\text {th }}$ ed. New York: McGraw-Hill Education; 2015.

19. Macbeth DK. Strategic Analysis of Supply Chain Design. United Kingdom: Bookboon; 2015.

20. Popovich L. Pharmaceutical market perspectives in Russia. Int J Healthc Manage. 2013;6(1):63-5.

21. Porter ME. Competitive Strategy: Techniques for Analyzing Industries and Competitors. New York: The Free Press; 2017.

22. Bogomolova YV. SWOT analysis: Theory and practice of application. Econ Anal. 2004;17(32):57-60.

23. Izosimov SV, Shevchenko AL. The method of SWOT analysis: Its place in research methods, advantages and disadvantages. Economics. 2013;2:29-34.

24. Hoq MR, Ahsan MA, Tabassum TA. A study on SWOT analysis of pharmaceutical industry: The Bangladesh context. Global Dis Econ Bus. 2013; 2(2):200-8.

25. Patel MM, Shah PJ, Patel BM. Insights of biosimilars through SWOT analysis. Expert Opin Biol Ther. 2014;14(2):139-44. https://doi.org/10.1517/14712598.2014.849689 PMid:24151903

26. Paul DR. Propositions on the pharmaceutical marketing system. J Pharm Mark Manage. 2002;14(3-4):75-85. https://doi. org/10.1300/j058v14n03_05

27. Perreault WD Jr., Cannon JP, McCarthy EJ. Essentials of Marketing: A Marketing Strategy Planning Approach. Boston: McGraw-Hill//rwin; 2013

28. Valentin EK. SWOT Analysis from a resource-based view. J Mark Theory Pract. 2001;9(2):54-69.

29. Krasnokutsky AB, Lagunova AA. Pharmacoeconomics. In: System Analysis of the Global Pharmaceutical Market. Vol. 1. Moscow: Classic Consulting; 1998.

30. Cundari A. Customer-centric Marketing. Build Relationships, Create Advocates, and Influence Your Customers. United States: John Wiley \& Sons Limited; 2015

31. Federal State Statistics Service. The Effectiveness of the Russian Economy. Available from: https://www.gks.ru. [Last accessed on 2020 Aug 20].

32. Harrison DL, Bootman JL. Strategic planning for institutional pharmacy administrators. J Pharm Mark Manage. 1990;5(1):2943. https://doi.org/10.3109/j058v05n01_03

33. Grewal D, Levy M. Marketing. New York: McGraw-Hill//rwin; 2014.

34. Kavoura A, Sakas DP. Strategic Innovative Marketing. $4^{\text {th }}$ IC-SIM, Mykonos, Greece 2015. Berlin, Germany: Springer; 2015. https://doi.org/10.1007/978-3-319-33865-1

35. Saha A, Roberts H. Pharmaceutical industry's changing market dynamics. Int J Econ Bus. 2020;27(2):1-17.

36. Smith BD, Awopetu B. Mind-set and market segmentation in the pharmaceutical industry: An assessment of practice in the UK. J Pharm Mark Manage. 2006;17(3-4):101-16. https:// doi.org/10.1300/j058v17n03_07

37. Stros $M$, Lee $N$. Marketing dimensions in the prescription pharmaceutical industry: A systematic literature review. J Strat Mark. 2015;23(4):318-36. https://doi.org/10.1080/09652 $54 x .2014 .931878$

38. Wheeler N, Proctor T. Strategy analysis in the health service. J Mark Manage. 1993;9(3):287-300. 